Third and finally, let me speak to the concern articulated by Martin Barker, but I think behind nearly all of the opposition to sociobiology and like enterprises. When all is said and done, is it not really the case that sociobiology is merely right-wing ideology dressed up to look like genuine science? One would have to be insensitive not to recognize this as a genuine concern, or to deny that genetic theories of human behaviour have been (and still are) used to "support" some pretty horrible social doctrines. But it is simply not true to claim unequivocally that all genetic theories are apologia for the worst excesses of Western capitalism, any more than it would be true to claim that all environmentalist theories are as ideologically pure as the driven snow. Indeed, some thoroughly dreadful practices have been pushed by people who claim that all we need is a little of the right social conditioning.

In short, I remain unconvinced that sociobiology is the inherently evil thing supposed by the DBG. No doubt the members of the DBG will remain equally unconvinced of what I say. But could I make one request? Do not let us degenerate into accusations that the other side is responsible for the rise and success of Creationism - as the cover of one of these books suggests. There is simply no causal connexion between sociobiology and Creationism, and to pretend otherwise is gratuitously insulting. For all our differences, do not forget that we are all striving, painfully, to see the light.

Michael Ruse is a Professor in the Departments of History and Philosophy at the University of Guelph. His most recent book is Darwinism Defended (Addison-Wesley, 1982).

\section{Journals' review issue 1982}

On October 7 th Nature will publish a second review supplement devoted to science journals. Last year's supplement, covering journals first published between January 1978 and May 1980, appeared in Nature 293, 341-369; see p. 343 of that issue for details.

Criteria for inclusion of a journal in the 1982 issue are that:

- the first number appeared, or the journal was re-titled, between June 1980 and May 1981;

- it is published at least three times a year;

- the main language used is English.

Broadly, periodicals of professional interest to scientists will be considered for review, with the exception of abstracts' journals.

In addition it is hoped to cover publicly available newsletters, first published between January 1978 and May 1981, in that issue.

Publishers and societies are invited to submit four sample issues of periodicals satisfying the above criteria, including the first and most recent numbers, to the Review Editor, Nature, 4 Little Essex St, London WC2R 3LF, England (London 8366633 ext 2570) as soon as possible.

\title{
The biological roots of personality
}

\section{Anthony Gale}

A Model for Personality. Edited by H. J. Eysenck. Pp.287. ISBN 3-540-10318-X/ 0-387-10318-X. (Springer-Verlag: 1981.) DM78, \$37.20.

AT THE dinner last summer to celebrate the publication of his Festschrift, Hans Eysenck declared himself to be confused. This unusual state of mind resulted from a paradox. The same scientific thinking which had led him to reject fascism in his youth had created enemies in his old age. His analysis of IQ differences between ethnic groups, and his insistence that biological factors account for differences between individuals, have led to accusations of racism. Eysenck-bashing has become a popular sport, not only on the campus, but in scientific journals. $\mathrm{He}$ only needed to look to his own writings for an answer to the paradox; frequently he talks of the zeitgeist, the prevailing scientific fashion which favours some approaches and castigates others. And he has never been afraid to profess unpopular views, whether it be to attack psychoanalysis or to accuse his fellow psychologists of sloppy thinking.

In A Model for Personality Eysenck invites his critics to do their worst. His theory of the biological basis of extraversion, and the data which support it, are laid out before us, warts and all. He sees himself in a long line of biological theorists, stretching back to the Greek physician, Galen. The argument is straightforward: systematic studies of personality reveal two common factors, extraversionintroversion and neuroticism-stability; and their ubiquitous appearance implies that they are given by nature. If they have biological roots, we expect them to be normally distributed across the population, to be transmitted by genetic mechanisms, expressed in brain function, and adaptive in governing the interaction of the individual with his physical and social environment. Each of the contributors to the book (all are internationally established authorities) deals with one of these aspects of the theory.

The reader should recognize that, for many psychologists, the establishment of links between genetics, biology, learning, and the way people think and interact socially involves a tremendous imaginative leap into the unknown, for it presupposes that all the philosophical problems raised by the Mind-Body relationship will ultimately be resolved. Some of the tricks, which involve a shift between diverse domains of description, are truly remarkable. For example, a 24-item paper and pencil test about how you feel in different situations ("Would you rather stay at home, or go to a dull party?") enables successful prediction of electrical properties of the brain. Eysenck believes, as did Pavlov, that nervous systems qua nervous systems, have properties which determine the ways in which the organism acts upon and responds to the environment. The Dynamics of Anxiety and Hysteria (Routledge \& Kegan Paul, 1957) and The Biological Basis of Personality (Thomas, 1967) showed how Eysenck's theory could find operational expression in the form of systematic laboratory experiments. This rapprochement between traditional experimental psychology and personality theory is illustrated by his son Michael's chapter, reviewing studies of personality, learning and memory.

The penultimate chapter, by Jeffrey Gray, offers a savage critique of the theory. He claims that Eysenck's selection of a particular mathematical solution to factor data does not fit the facts, that every data set supporting the theory is matched by a contradictory set, that the 1957 and 1967 versions generate different and even conflicting predictions, and that the key instrument of measurement (the Eysenck Personality Inventory) has undergone surreptitious changes over the years. Only Eysenck could invite a colleague (possibly his successor at the Institute of Psychiatry?) to write such a provocative and thoroughgoing critique of his own theory.

This is a very useful, balanced and sensibly compiled record of Eysenck's progress in this his retirement year. It is ironic that in the 1980s there is a move towards a more biological perspective: the pendulum is swinging back in Eysenck's direction.

Anthony Gale is Professor of Psychology at the University of Southampton. He is co-editor of The Biological Bases of Personality and Behaviour (Hemisphere Press, 1982) and Psychology and People: A Tutorial Text (BPSMacmillan, 1982).

\section{Chariots of water}

\section{Ian Phillips}

Thirst. By Barbara J. Rolls and Edmund T. Rolls. Pp.194. Hbk ISBN 0-521-22918-9; pbk ISBN 0-521-29718-4. (Cambridge University Press: 1982.) Hbk £15, \$29.50; pbk $£ 5.50, \$ 10.95$.

EVERY year in London on the neutral waters of the Thames there is a race between a row-boat from Cambridge University and one from Oxford. I was reminded of this when asked to review Thirst by Barbara Rolls and Edmund Rolls from Oxford University, since a year ago I 